University of Wollongong

Research Online

Faculty of Informatics - Papers (Archive)

Faculty of Engineering and Information

Sciences

$1-1-2001$

\title{
Application of a fuzzy controller to seismically excited nonlinear buildings
}

\author{
Mohammed Al-Dawod \\ University of Technology, Sydney \\ Bijan Samali \\ University of Technology, Sydney \\ Kenny Kwok \\ University of Sydney \\ Fazel Naghdy \\ University of Wollongong, fazel@uow.edu.au
}

Follow this and additional works at: https://ro.uow.edu.au/infopapers

Part of the Physical Sciences and Mathematics Commons

\section{Recommended Citation}

Al-Dawod, Mohammed; Samali, Bijan; Kwok, Kenny; and Naghdy, Fazel: Application of a fuzzy controller to seismically excited nonlinear buildings 2001, 151.

https://ro.uow.edu.au/infopapers/869

Research Online is the open access institutional repository for the University of Wollongong. For further information contact the UOW Library: research-pubs@uow.edu.au 


\title{
Application of a fuzzy controller to seismically excited nonlinear buildings
}

\author{
Abstract \\ Focuses on the benchmark control problems for seismically excited nonlinear buildings defined by Ohtori \\ et al. (2000). This benchmark study focuses on three typical steel structures, 3-, 9- and 20-storey buildings \\ designed for the SAC project for Los Angeles in the California region. The first stage of applying the fuzzy \\ controller to this benchmark study for the 3-storey building is reported. The main advantage of the fuzzy \\ controller is its inherent robustness and ability to handle the non-linear behaviour of the structure. This \\ benchmark study is based on a number of evaluation criteria and control constraints and these \\ limitations are considered in the design of the fuzzy controller. The performance of the controller is \\ validated through the computer simulation on MATLAB. The results of the simulation show a good \\ performance of the fuzzy controller to reduce the response of the building under different earthquake \\ excitations \\ Keywords \\ nonlinear, excited, buildings, seismically, application, controller, fuzzy \\ Disciplines \\ Physical Sciences and Mathematics \\ Publication Details \\ F. Naghdy, M. Aldawod, B. Samali \& K. Kwok, "Application of a fuzzy controller to seismically excited \\ nonlinear buildings," in 2001 IEEE International Fuzzy Systems Conference, 2001, p. 151.
}




\author{
Mohammed Al-Dawod ${ }^{1}$, Bijan Samali ${ }^{1}$, Kenny Kwok ${ }^{2}$ and Fazel Naghdy ${ }^{3}$ \\ 1. Center for Built Infrastructure Research; $\mathrm{PhD}$ candidate, Professor of Structural Engineering, Faculty of Engineering, \\ University of Technology Sydney, NSW 2007 Australia \\ 2. Department of Civil Engineering, University of Sydney, NSW, 2006, Australia \\ 3. School of Electrical, Computer \& Telecommunication Engineering, University of Wollongong, NSW, 2500, Australia
}

\begin{abstract}
This paper focuses on the benchmark control problems for seismically excited nonlinear buildings defined by Obtori et al, [1]. This benchmark study focuses on three typical steel structures, 3-, 9- and 20-storey buildings designed for the SAC project for Los Angeles in California region. The first stage of applying the furcy controller to this benchmark study for the 3-storey building is reported. The main advantage of the fozzy controller is its inherent robustness and ability to handle the non-linear behaviour of the structure. This benchmark study is based on a number of evaluation criteria and control constraints and these limitations are considered in the design of the fuzzy controller. The performance of the controller is validated through the computer simulation on MATLAB. The results of the simulation show a good performance of the fuxzy controller to reduce the response of the building under different earthquake excitations. In the next stage, the study of the fuzzy controller will be extended to the 9and 20 -storey buildings specified in this benchmark study.
\end{abstract}

\section{INTRODUCTION}

The protection of civil engineering structures from environmental loads such as strong wind and severe earthquake, including their impact on building contents and occupants, is a worldwide priority. Passive, semi-active and active schemes are becoming an integral part of the structural systems over the past two decades [2-3].

Most of the studies in the area of structural control have focused on the application of the linear control theory, because of the large body of proven linear control methods available and the tendency of keeping the structural response in the linear range. The mathematical model used for tall buildings is usually linear. However, such a model does not fully represent the behaviour of the building when subjected to severe wind or earthquake.

The main objective of this work is to apply an intelligent controller, fuzzy logic controller, to the benchmark building of 3-storeies defined by Ohtori et al [1] to handle the non-linearity of the system. Fuzzy logic is one of the model free approaches to system identification and control. A fuzzy logic controller is robust and capable of handling nonlinear behaviour of the structure. The main advantages in adopting a fuzzy control scheme can be summarized as follows:

- The uncertainties of the input data from the wind or earthquake and structural vibration sensors are treated in a much easier way by fuzzy control theory than by classical control theory. Fuzzy logic, which is the basis of the fuzzy controller, intrinsically accounts for such uncertainties. The implementation of fuzzy controllers makes use of linguistic synthesis and therefore they are not affected by the selection of a specific mathematical model. As a consequence, the resulting fuzzy controller possesses an inherent robustness.

- Fuzzy controller has the ability to handle the nonlinear behavior of the structure. The linear models do not include disturbances caused by large displacement or material nonlinearity and damage.

- The whole fuzzy controller can be easily implemented in a fuzzy chip, which guarantees immediate reaction times and autonomous power supply.

In the course of paper, the building under consideration and the fuzzy controller will be described and the results presented and analyzed.

\section{BENCHMARK STRUCTURE}

The building used in this work is the 3-storey benchmark structure defined by Ohtori et al [1]. The building is $36.58 \mathrm{~m}$ by $54.87 \mathrm{~m}$ in plan, and $11.89 \mathrm{~m}$ in height. The bays are 9.15 $\mathrm{m}$, in both directions, with four bays in the north-south (N-S) direction and six bays in the east-west (E-W) direction. The seismic mass of the entire structure is $2.95 \times 10^{6} \mathrm{~kg}$. The first three natural frequencies of the building are $0.99,3.06$ and 5.83 $\mathrm{Hz}$, respectively. The 3-storey N-S frame is shown in "Fig. 1". The three-mode shapes for the 3-storey building model are shown in "Fig. 2".

\section{A. Nonlinear Analysis}

During large seismic events, structural members can yield, resulting in nonlinear response behaviour that may be significantly different than a linear approximation. Therefore, an efficient implementation of the Newmark-time-step integration method was developed in MATLAB for this purpose [4].

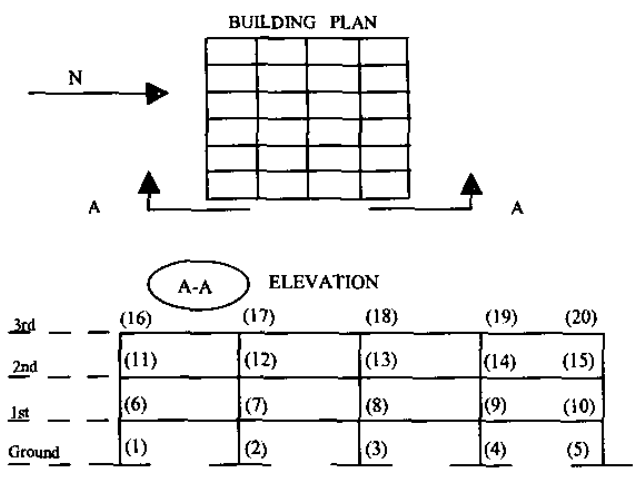

Fig. 1. 3-Storey benchmark building N-S direction 


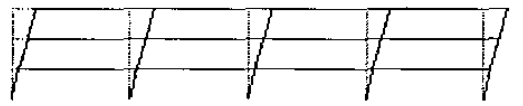

Mode $1(0.99 \mathrm{~Hz})$

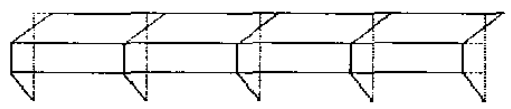

Mode 2 (3.06 Hz)

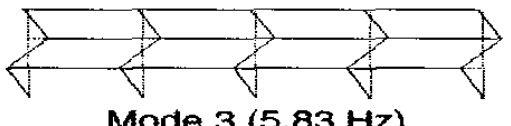

Mode $3(5.83 \mathrm{~Hz})$

Fig. 2. Mode shapes for the 3-storey building

The Newmark method is used to solve the incremental equation of motion. The incremental equation of motion for the nonlinear structural system takes the following form:

$$
\mathrm{M} \Delta \ddot{\mathrm{U}}+\mathrm{C} \Delta \dot{\mathrm{U}}+\mathrm{K} \Delta \mathrm{U}=-\mathrm{MG} \Delta \ddot{\mathrm{x}}_{\mathrm{g}}+\mathrm{P} \Delta \mathrm{f}+\Delta \mathrm{F}_{\mathrm{er}}
$$

Where, $\mathrm{M}, \mathrm{C}, \mathrm{K}$ are mass, damping and stiffness matrices of the building, $\Delta U$ is the incremental response vector, $G$ is a loading vector for the ground acceleration, $\Delta \ddot{\mathrm{x}}_{\mathrm{g}}$ is the ground acceleration increment, $P$ is a loading vector for the control force, $\Delta f$ is the incrmental control force and $\Delta F_{\text {err }}$ is the vector of unbalanced forces. The unbalanced force is the difference between the restoring force evaluated using the hysteresis model and the restoring force assuming constant linear stiffness at time $t$ during the time interval $(t, t+\Delta t)$. This unbalanced force is handled at the next time step.

\section{B. Evaluation Criteria}

In order to evaluate the performance of the fuzzy controller, two far-field and two near-field historical ground motion records are selected: El Centro 1940, Hachinohe 1968, Northridge 1994 and Kobe 1995 earthquakes. The absolute peak acceleration of the earthquake records are $0.3417,0.2250$, 0.8267 and $0.8178 \mathrm{~g}$, respectively as shown in "Fig. 3". The evaluation criteria are divided into four categories: building response, building damage, control devices and control requirements.
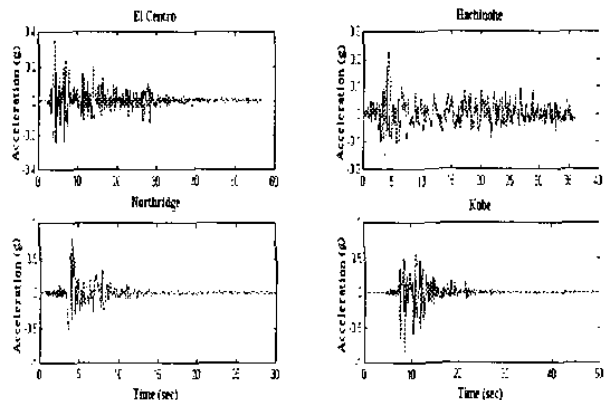

Fig. 3. Time histories of earthquake records used: El Centro; Hachinohe; Northridge; Kobe
The first three criteria are based on the ratio of peak interstorey drift $\left(\mathrm{J}_{1}\right)$, floor acceleration $\left(\mathrm{J}_{2}\right)$ and base shear $\left(\mathrm{J}_{3}\right)$. The next three criteria are based on the ratio of normed inter-storey drift $\left(\mathrm{J}_{4}\right)$, floor acceleration $\left(\mathrm{J}_{5}\right)$ and base shear $\left(\mathrm{J}_{6}\right)$. The seventh and eighth criteria are the ductility factor $\left(\mathrm{J}_{7}\right)$ and dissipated energy of the curvatures at the end of members $\left(J_{8}\right)$. The ninth criterion $\left(J_{9}\right)$ is the ratio of the plastic connections sustained by the structure and $\left(\mathrm{J}_{10}\right)$ criterion is the normed ductility factor. $\left(J_{11}\right),\left(J_{12}\right)$ and $\left(J_{13}\right)$ criteria show the peak control force, the peak control device stroke and the peak power used for control, respectively and $\left(\mathrm{J}_{14}\right)$ criterion is a measure of total power for the control of the structure. The last three criteria $\left(J_{15}\right),\left(J_{16}\right)$ and $\left(J_{17}\right)$ are the total number of control devices implemented to control the benchmark building, the number of control sensors used for the control and the assessment of the computational resources required for the control algorithm, respectively. For more details refer to the Ohtori et al [1].

\section{FUZZY LOGIC CONTROLLER}

Fuzzy logic, introduced by Zadeh, [5], enables the use of linguistic directions as a basis for control. Generally very robust and capable of handling nonlinear systems, fuzzy logic controllers (FLC) usually require expert knowledge in their construction. The most widely used fuzzy control inference $M$ is the "if-then" rule, which can be written as follows when two input data are used in their antecedent parts [6]:

$$
M^{i}: \text { if } X_{1}=A_{i} \text { and } X_{2}=B_{i} \text { then } Y=C_{i}
$$

Where $i$ is the number of control rules. $X_{1}$ and $X_{2}$ are the variables of the antecedent parts. $Y$ is the variable of the sequent part. $A_{i}, B_{i}$, and $C_{i}$ are the fuzzy variables. The basic structure of a typical fuzzy logic controller has four components; Fuzzification, Knowledge Base, Decision Making and Defuzzification. In this paper, the preliminary design of the controller will couple the Larsen's minimum product rule [7], to combine the membership values for each rule, with the center of gravity (COG) defuzzification scheme, to obtain the output crisp value.

\section{FUZZY CONTROLLER DESIGN}

The fuzzy controller uses crisp data directly from a number of sensors; these data are then converted into linguistic or fuzzy membership functions through the fuzzification process. The number of sensors used in the system is dependent on the number of input variables used in the controller.

The controller is designed using two input variables, each one having seven membership functions, and one output variable with eleven membership functions. The membership functions chosen for the input and output variables are triangular shaped as illustrated in "Figs. 4 and 5", respectively. The fuzzy variables used to define the fuzzy space are described in Table 1. The self-organizing fuzzy logic controller (SOFLC) is used to find the final Fuzzy Associative Memory (FAM) as shown in Table II. The fuzzy controller is implemented into the SIMULINK program, shown in "Fig. 6", 
using an integration time step of 0.005 seconds and the control signal is computed every 0.005 seconds.

The control actuators are located on each storey of the structure to provide forces to adjacent floors. The size of the actuators is limited to provide a maximum control force of $1000 \mathrm{kN}$ and actuators with this capacity are readily available. To provide larger forces, five actuators are employed on the $3^{\text {rd }}$ floor and one actuator on both the $1^{\text {st }}$ and $2^{\text {nd }}$ floors. Each actuator is implemented in the structure using a chevron brace configuration, in which the actuator is horizontal and rigidly attached between two consecutive levels of the building. Thus, the actuators placed on the first level will produce equal and opposite control forces on the first and second floors. The fuzzy controller is implemented on each floor as shown in Fig. 7.

TABLE I

FuZZY VARIABLES

\begin{tabular}{|c|l|}
\hline PVL & Positive and Very Large \\
PL & Positive and Large \\
PM & Positive and Medium \\
PS & Positive and Small \\
PVS & Positive and Very Small \\
ZR & Zero \\
NVS & Negative and Very Small \\
NS & Negative and Small \\
NM & Negative and Medium \\
NL & Negative and Large \\
NVL & Negative and Very Large \\
\hline
\end{tabular}

TABLE II

FuZZy AsSOCIATTVE MEMory (FAM) of THE FuZzy CONTROLLER $2^{\mathrm{ND}}$ Input

\begin{tabular}{|c|c|c|c|c|c|c|c|}
\hline $\mathbf{U}$ & NL & $\mathrm{NM}$ & NS & ZR & PS & PM & PL \\
\hline NL & $\mathrm{NVL}$ & $\mathrm{NL}$ & NM & NS & PVS & $\overline{\mathrm{PS}}$ & $\mathrm{PM}$ \\
\hline $\mathrm{NM}$ & $\mathrm{NL}$ & $\mathrm{NM}$ & NS & NS & PVS & PS & $\mathrm{PM}$ \\
\hline $\mathrm{NS}$ & NM & NS & NVS & NVS & PVS & PS & $\mathrm{PM}$ \\
\hline ZR & NM & $\mathrm{NS}$ & NVS & $\mathrm{ZR}$ & PVS & PS & $P M$ \\
\hline PS & $\overline{\mathrm{NM}}$ & NS & NVS & PVS & PVS & PS & $\overline{P M}$ \\
\hline $\mathrm{PM}$ & $\mathrm{NM}$ & NS & NVS & PS & PS & $\mathrm{PM}$ & $\mathrm{PL}$ \\
\hline $\mathrm{PL}$ & NM & NS & NVS & PS & PM & PL & PVL \\
\hline
\end{tabular}

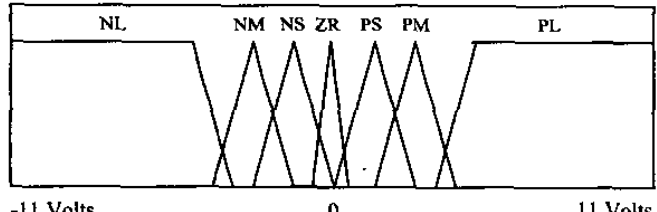

Fig. 4. Membership function for the acceleration of the $1^{\text {st }}$ and the $2^{\text {nd }}$ input

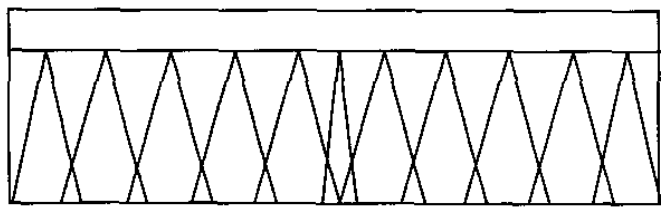

-12 Volts

12 Volts

Fig. 5. Membership function for the control force

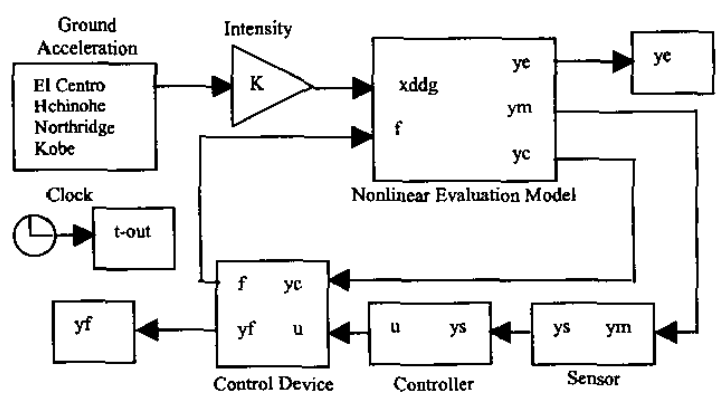

Fig. 6. 3-Storey SIMULINK block diagram for vibration control simulator

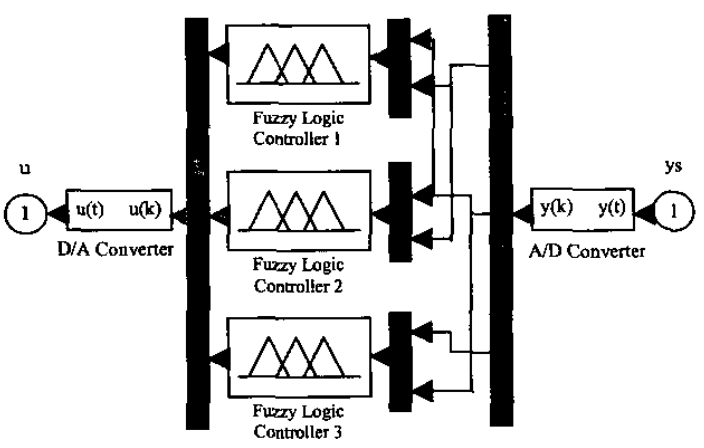

Fig. 7. SIMULINK block representing the fuzzy controller

\section{CONTROL PERFORMANCE}

The performance of the fuzzy controller is checked according to the evaluation criteria specified $\left(J_{1}-J_{17}\right)$. These criteria are. calculated as a ratio of the controlled and the uncontrolled responses. The uncontrolled response calculated is the maximum value due to four earthquake records used in the simulation and these values are compared with the controlled results for each of the four earthquake records. In this study, five actuators are employed on the $3^{\text {rd }}$ floor with a maximum control force of $907.2 \mathrm{kN}$ for each actuator and one actuator employed on the $1^{\text {st }}$ and $2^{\text {nd }}$ floors with a maximum control force of $0.96 \mathrm{kN}$. The force required for the $1^{\text {st }}$ and $2^{\text {nd }}$ floors is very small compared to the force required for the $3^{\text {nd }}$ floor and as a result, it is possible to have a simple bracing installed in $1^{\text {st }}$ and $2^{\text {nd }}$ floors without any actuators and reduce the cost of the system in the process.

Table III shows the results of the peak uncontrolled and controlled responses of the 3-storey benchmark building. For the uncontrolled response, the table shows that the largest response is associated with Kobe and Northridge Earthquake records. Also, These results show the ability of the fuzzy controller to reduce the response of the building for the four earthquake records but this reduction is varied between them. For El Centro and Hachinohe earthquake records, the reductions in terms of peak displacement are $13 \%$ and $25 \%$, respectively, and in terms of peak acceleration are only $3 \%$ and $10 \%$, respectively but still well away from the maximum response case. For Kobe and Northridge earthquake records, the reductions in terms of peak displacement are $15 \%$ and $22 \%$, 
respectively, and in terms of peak acceleration are $31 \%$ and $14 \%$, respectively.

Table IV shows the earthquake evaluation criteria $\left(\mathrm{J}_{1}-\mathrm{J}_{17}\right)$ for the 3-storey benchmark building. The results show a reasonable performance of the fuzzy controller in reducing the peak drift ratio, peak acceleration level, peak base shear and plastic connections for the four earthquake records. Meanwhile, the performance is slightly worse for the norm drift ratio, norm base shear, ductility and energy dissipation especially for the Kobe record. Another advantage of the fuzzy controller is that it does not need any computation resources as illustrated in Table IV, $\left(J_{17}=0\right)$.

\section{CONCLUSIONS}

In this paper, the focus of the study was on the benchmark control problems for seismically excited nonlinear buildings defined by Ohtori et al, [1]. The first stage of applying the fuzzy controller to this benchmark study for the 3-storey building was reported. Fuzzy logic controller was adopted to drive the control system. The performance of the fuzzy controller was checked thorough a number of evaluation criteria specified for this benchmark study.

The performance of the fuzzy controller was checked for four earthquake records: El Centro 1940, Hachinohe 1968, Northridge 1994 and Kobe 1995. The results of the simulation show the ability of the fuzzy controller to reduce the response of the building due to the four earthquake records. In the next stage of the study, the fuzzy controller will be implemented in the 9- and 20-storey buildings specified in this benchmark study.

\section{ACKNOWLEDGMENT}

The authors would like to acknowledge the financial contributions received from the Australian Research Council under Large Grant Scheme (No. A89773) and from the University of Technology, Sydney through Center of Built Infrastructure Research in support of this project.

TABLE III

PEAK RESPONSE OF THE 3.STOREY BENCHMARK BUILDING WTY AND WTTHOUT CONTROL

\begin{tabular}{|c|c|c|c|c|c|}
\hline & & El Centro & Hachinohe & Northridge & Kobe \\
\hline Displacement & L1 & 0.047 & 0.041 & 0.100 & 0.086 \\
No Control & L2 & 0.103 & 0.099 & 0.187 & 0.193 \\
(m) & L3 & 0.151 & 0.147 & 0.272 & 0.307 \\
\hline Displacement & L1 & 0.054 & 0.050 & 0.106 & 0.116 \\
with Control & L2 & 0.106 & 0.095 & 0.194 & 0.235 \\
(m) & L3 & 0.132 & 0.110 & 0.212 & 0.263 \\
\hline Velocity & L1 & 0.315 & 0.333 & 0.737 & 0.656 \\
No Control & L2 & 0.571 & 0.580 & 0.970 & 0.951 \\
(m/sec) & L3 & 0.955 & 0.890 & 1.411 & 1.875 \\
\hline Velocity & L1 & 0.370 & 0.268 & 0.647 & 0.711 \\
with Control & L2 & 0.702 & 0.559 & 1.178 & 1.255 \\
(m/sec) & L3 & 0.809 & 0.676 & 1.299 & 1.684 \\
\hline Acceleration & L1 & 4.180 & 4.401 & 9.590 & 12.04 \\
No Control & L2 & 5.359 & 4.867 & 9.078 & 10.53 \\
(m/sec ${ }^{2}$ ) & L3 & 6.539 & 6.480 & 8.590 & 8.835 \\
\hline Acceleration & L1 & 5.010 & 4.332 & 8.185 & 6.340 \\
with Control & L2 & 5.763 & 5.879 & 8.333 & 8.268 \\
(m/sec ${ }^{2}$ ) & L3 & 6.350 & 5.200 & 7.106 & 7.871 \\
\hline
\end{tabular}

TABLE TV

Earthouake Evaluation Criteria for the 3-Storiey Benchmark BuIldino

\begin{tabular}{|c|c|c|c|c|}
\hline & El Centro & Hachinobe & Northridge & Kobe \\
\hline $\begin{array}{c}\mathrm{J}_{\mathrm{l}} \\
\text { Peak Drift Ratio }\end{array}$ & 0.397 & 0.345 & 0.729 & 0.842 \\
\hline $\begin{array}{c}\mathrm{J}_{2} \\
\text { Peak Level } \\
\text { Acceleration }\end{array}$ & 0.528 & 0.489 & 0.692 & 0.687 \\
\hline $\begin{array}{c}\mathrm{J}_{3} \\
\text { Peak Base Shear }\end{array}$ & 0.758 & 0.763 & 0.952 & 0.940 \\
\hline $\begin{array}{c}J_{4} \\
\text { Norm Drift Ratio }\end{array}$ & 0.271 & 0.311 & 0.846 & 1.179 \\
\hline $\begin{array}{c}\mathrm{J}_{5} \\
\text { Norm Level } \\
\text { Acceleration }\end{array}$ & 1.001 & 1.038 & 0.890 & 1.057 \\
\hline $\begin{array}{c}\mathrm{J}_{6} \\
\text { Norm Base Shear }\end{array}$ & 1.096 & 1.198 & 0.999 & 1.166 \\
\hline $\begin{array}{c}J_{7} \\
\text { Ductility }\end{array}$ & 0.489 & 0.457 & 1.057 & 1.124 \\
\hline $\begin{array}{c}J_{8} \\
\text { Dissipated Energy }\end{array}$ & 0.610 & 0.200 & 0.876 & 2.036 \\
\hline $\begin{array}{c}\mathrm{J}_{9} \\
\text { Plastic Connections }\end{array}$ & 0.364 & 0.364 & 0.818 & 0.939 \\
\hline $\begin{array}{c}J_{10} \\
\text { Norm Ductility }\end{array}$ & 0.318 & 0.362 & 1.198 & 1.422 \\
\hline $\begin{array}{c}\quad \widetilde{\mathrm{J}_{11}} \\
\text { Control Force }\end{array}$ & 0.031 & 0.031 & 0.031 & 0.031 \\
\hline $\begin{array}{c}3_{12} \\
\text { Device Stroke }\end{array}$ & 0.431 & 0.357 & 0.691 & 0.857 \\
\hline $\begin{array}{c}\mathrm{J}_{13} \\
\text { Control Power }\end{array}$ & 0.060 & 0.039 & 0.077 & 0.136 \\
\hline $\begin{array}{c}J_{14} \\
\text { Norm Control Power }\end{array}$ & 0.055 & 0.059 & 0.051 & 0.075 \\
\hline $\begin{array}{c}J_{15} \\
\text { Control Devices }\end{array}$ & 7 & 7 & 7 & 7 \\
\hline $\begin{array}{c}\mathbf{J}_{16} \\
\text { Sensors }\end{array}$ & 3 & 3 & 3 & 3 \\
\hline $\begin{array}{c}\mathbf{J}_{17} \\
\text { Computation } \\
\text { Resources }\end{array}$ & 0 & 0 & 0 & 0 \\
\hline
\end{tabular}

\section{REFERENCES}

[1] Y. Ohtori, R. E. Christenson, B. F. Spencer Jr, and S. J. Dyke, "Benchmark Control Problems for Seismically Excited Nonlinear Buildings," http://www.nd.edu, 2000.

[2] M. Al-Dawod, F. Faghdy, B. Samali, and K. Kwok, "Active Control of Wind Excited Structures Using Fuzzy Logic," 8th IEEE International Conference on Fuzzy Systems, Seoul, Korea, vol. 1, pp. 72-77, August 1999.

[3] M. Al-Dawod, B. Samali, F. Naghdy, and K. Kwok, "Application of a Robust Fuzzy Controller to a wind Excited Structure," Asia-Pacific Vibration Control '99, Singapore, vol. 2, pp. 812-813, December 1999.

[4] Y. Ohtori and B. F. Spencer Jr, "A MATLAB-Based Tool for Nonlinear Structural Dynamics Analysis," 13th ASCE Engineering Mechanics Division Specialty Conference, Johns Hopkins University, Baltimore, pp. 13-16, June 1999.

[5] L. A. Zadeh, "Fuzzy Set," Information and Control, pp. 338-353, 1965.

[6] L.-X. Wang, Adaptive Fuzzy Systems and Control: Design and Stability Analysis. Englewood Cliffs, N.J.: PTR Prentice Hall, 1994.

[7] J. Yan, M. Ryan, and J. Power, Using Fuzzy Logic: Towards Intelligent Systems. New York: Prentice Hall, 1994. 